\title{
Perioperative observations of different bypass modes of a right coronary system based on instantaneous blood flow during the operation
}

\author{
Zhou Zhao ${ }^{1}$, Chun Fu², Li-xue Zhang ${ }^{1}$, Guo-dong Zhang ${ }^{1}$ and Yu Chen ${ }^{1 *}$ (i)
}

\begin{abstract}
Background: With the ageing of China's population, the incidence and mortality of coronary atherosclerotic heart disease (CAD) is increasing year by year, which brings a heavy burden to the family and society [1]. We aimed to analyse the strategy of coronary artery bypass grafting $(C A B G)$ in the right coronary artery and to compare the haemodynamic characteristics of the sequential grafts with those of single grafts and to observe the patency rate of those grafts for 1 week after the operation.

Methods: A total of 242 patients (178 men, mean age $62.6 \pm 8.8$ years) underwent right coronary artery bypass grafting in our hospital from October 2016 to January 2019. The blood flow (Q, ml/min), pulsatility index (PI) and related parameters of the grafts were measured and recorded by TTFM during the CABG. The patency of the grafts was evaluated by coronary computed tomography (CT) for 1 week after the operation.

(Continued on next page)
\end{abstract}

\footnotetext{
* Correspondence: chenyudoctor@163.com

'Cardiac Surgery Department, Peking University People's Hospital, Beijing 100044, China

Full list of author information is available at the end of the article
}

(c) The Author(s). 2020 Open Access This article is licensed under a Creative Commons Attribution 4.0 International License, which permits use, sharing, adaptation, distribution and reproduction in any medium or format, as long as you give appropriate credit to the original author(s) and the source, provide a link to the Creative Commons licence, and indicate if changes were made. The images or other third party material in this article are included in the article's Creative Commons licence, unless indicated otherwise in a credit line to the material. If material is not included in the article's Creative Commons licence and your intended use is not permitted by statutory regulation or exceeds the permitted use, you will need to obtain permission directly from the copyright holder. To view a copy of this licence, visit http://creativecommons.org/licenses/by/4.0/. The Creative Commons Public Domain Dedication waiver (http://creativecommons.org/publicdomain/zero/1.0/) applies to the data made available in this article, unless otherwise stated in a credit line to the data. 
(Continued from previous page)

Results: The most common material used for the graft in the right coronary system of CABG is the greater saphenous vein (92.3\%), followed by the radial artery (5.5\%) and the internal mammary artery (1.9\%). The highest frequency target of the right coronary artery is the posterior descending artery (PDA) (47.6\%), followed by the right main coronary artery (RCA) (29.1\%) and the posterior branch of the left ventricle (PL) (23.3\%). The proportion of single grafts was the highest for the right coronary artery in CABG (178 cases, 67.9\%), followed by a graft of the PDA-PL (42 cases, 16.0\%) and other sequential grafts among the different coronary artery systems (including the system of the left anterior descending artery (LAD) and the left circumflex (LCX)). Whether there were sequential grafts of the PDA-PL or other sequential grafts among the different systems of the coronary artery, the instantaneous flow of a group of sequential grafts was higher than that of a single graft, and the difference had statistical significance $(P<0.01)$. However, there were no significant differences in the flow between the groups of sequential grafts $(P=0.410)$. Diastolic flow (DF) in the group of sequential grafts of the right coronary system was better than that in the non-sequential group $(P<0.001)$, and the difference had statistical significance. There was no significant difference between the DF of the groups of the other system of sequential grafts and that of the right coronary sequential grafts. Coronary artery CT suggested that there were 11 cases of poorly developing grafts or stenosis and occlusion a week after the operation, and those phenomenon mainly occurred in the group with a single graft. There was only one case that was occluded in the group of other systems of sequential grafts, and statistically significant differences existed between the two groups $(P<0.01)$.

Conclusions: In our centre, the most common form of CABG in the right coronary artery system is a nonsequential vein bridge to the PDA. Whether there are sequential grafts of the PDA-PL or other sequential grafts among the different coronary artery systems, the instantaneous flow of a group of sequential grafts is higher than that of a single graft. DF in the group of sequential grafts of the right coronary system was better than that in the non-sequential group.

Keywords: Coronary artery bypass grafting, Transit-time flowmeter, Sequential grafts

\section{Background}

With the ageing of China's population, the incidence and mortality of CAD are increasing year by year, which brings a heavy burden to the family and society [1]. CABG has been recognized as one of the accepted standard protocols for the treatment of complex, multivessel coronary vasculopathy since it was first introduced in the 1970s [2, 3].

The surgical strategies for the right coronary system (including the right main trunk, the posterior descending branch, and the left ventricle branch) have been significantly individualized and differentiated [4], especially in the selection of target vessel sites. The strategy depends on the surgeon's clinical experience and habits because there is no recognized consensus model for the bypass or surgical strategy of the right coronary system. The purpose of this study was to observe and analyse the surgical strategy of the right coronary artery bypass graft in the conventional CABG population in our centre. The haemodynamic characteristics of the sequential bypass and nonsequential bypass vessels were compared and the patency rate at 1 week after the operation was observed.

\section{Research materials and methods Research data}

From October 2016 to March 2019, a total of 242 patients underwent coronary artery bypass surgery in our hospital, including 178 men and 64 women, with an average age of $62.6 \pm 8.8$ years. The average bypass count was $3.22 \pm 0.80$. A transient-flow flowmeter (TTFM) was used in all selected patients to measure the vascular flow parameters, and the corresponding results were recorded. Patients who used the radial artery as a bridge vessel were given nicardipine intravenously during the perioperative period, and they started taking diltiazem hydrochloride tablets orally (30 mg three times/day) after removal from mechanical ventilation.

A coronary CT examination was performed 1 week after the operation to observe the patency of the right coronary artery. All patients were routinely taking aspirin $100 \mathrm{mg} /$ day to the day before surgery, and routinely taking aspirin $100 \mathrm{mg} /$ day and plavix $75 \mathrm{mg} /$ day after removal from mechanical ventilation.

\section{Methods \\ Research methods}

TTFM was used to measure and record the related parameters, such as the mean graft flow (MGF) and pulsatility index (PI value). A coronary CT examination was performed 1 week after surgery. Inclusion criteria: 1, simple CABG patients; 2, the right coronary system for coronary artery bypass grafting; exclusion criteria: 1, patients with minimally invasive small incision single and/ or multiple coronary artery bypass grafts; 2 , patients, for 
various reasons, who did not undergo TTFM examinations during the operation; and 3 , patients who, 1 week after surgery, did not undergo coronary CT examinations for various reasons. All CABG operations were completed by three surgeons with seniority greater than the deputy chief physician, and their independent completion of CABG surgery exceeded 700 cases.

\section{Surgical methods}

All patients underwent endotracheal intubation combined with general anaesthesia. All patients underwent routine mid-opening. Low-frequency electrosurgical detachment of the left (right) lateral mammary artery and/ or brachial artery was conducted under endoscope or direct vision. The saphenous vein collection and the coronary artery bypass grafting occurred under cardiohepatic cardiopulmonary bypass or non-stop jumping.

\section{Instruments and methods}

The transient blood flow meter (TTFM) used during the surgery is the Medidist VQ2011 model. After the anastomosis of all of the bypass vessels was completed, the protamine was neutralized and stabilized according to the diameter of the bypass. The ultrasonic probe was selected according to the diameter of the bypass, and the bypass vessel was placed in the probe near the anastomosis for direct measurement [5]. Parameters obtained during surgery: 1 . MGF is the average blood flow per minute in the graft bypass blood vessels, and the unit is $\mathrm{ml} / \mathrm{min}$. Some studies have suggested that MGF $<15 \mathrm{ml} /$ $\mathrm{min}$ is one of the predictors of a poor short-term prognosis [6]. 2. PI is the ratio of the maximum blood flow and the minimum blood flow difference to the mean flow rate $[\mathrm{PI}=(\mathrm{Q} \max -\mathrm{Q} \min ) / \mathrm{Qm}]$ in the graft vessel. It is one of the most commonly used indicators of graft function and is used to evaluate CABG with intraoperative TTFM. Excessive PI values represent functional defects in the transplanted blood vessels [7]. Different studies have different definitions of cut-off values for PI. It is generally considered that greater than 5 is considered to be an independent risk factor for graft vascular dysfunction [6]. 3. DF is the ratio of the diastolic blood flow to the sum of the systolic and diastolic blood flow $[\mathrm{DF}=\mathrm{Q}$ diastole $/(\mathrm{Q}$ systole $+\mathrm{Q}$ diastole $)]$, which is a good indicator for evaluating the function of the CABG graft. It is generally believed that DF $>50 \%$ is one of the indicators of good graft function [8].

\section{Intraoperative determination of flow satisfaction criteria}

1 . The coupling degree is satisfactory when measuring the graft bypass vessel (>50\% or more); 2 . The TTFM shows that the blood flow waveform is stable and reproducible; 3 . The average flow red line is recorded after the plateau period is stable; 4 . According to a previous study, display PI value $<5$, flow rate $>15 \mathrm{ml} / \mathrm{min}$ is a satisfactory bypass blood flow parameter.

\section{Postoperative coronary CT evaluation method}

The vascular patency or restenosis was evaluated by two senior radiologists. The diameter of the bypass was measured in the cross-section of the bypass vessel. The mean value of the vascular diameter of the stenosis was not used as a reference. According to the Fitzgibbon bypass vascular grading criteria [9]: Grade A, bypass vessel no stenosis or stenosis $<50 \%$; grade $B$, vascular stenosis $\geq 50 \%$, but not completely occluded; grade $\mathrm{O}$, complete occlusion of the bypass vessel. In this study, we classified the grade $\mathrm{A}$ into the patency group, classified the grade $\mathrm{B}$ and grade $\mathrm{O}$ into the stenosis group, and classified the poorly developed ones into the stenosis group.

\section{Statistical analysis}

All recovered data were analysed using EpiDate3.1 software, and the data were entered in parallel twice. The input data were logically checked, collated, and analysed for abnormal values to form a final analysis database. Correlation analysis was performed using the SPSS 20.0 statistical software package.

All descriptive measurement data are expressed by mean \pm standard deviation, and normal distribution data mean comparisons were conducted using variance analysis, and non-normal distribution data mean comparisons were conducted using nonparametric tests (ranksum tests). The comparisons between the groups were performed using a chi-square test.

\section{Results}

A total of 242 patients were included in this study, including 178 men and 64 women. Their average age was $62.6 \pm 8.8$ years, and the average number of bypasses was $3.22 \pm 0.803$. The specific results are shown in Table 1 .

This study showed that the proportion of nonsequential single-branched bypass in the right coronary system was the largest (178 cases, 67.9\%), followed by the sequential bypasses between the right posterior descending branch and the left ventricle posterior (42 cases, $16.0 \%$ ). The rest were mostly sequential bypasses between the right crown system and the non-right crown system (including the front descending branch system and the gyroscopic branch system) (see Table 2).

Considering the convenience of subsequent statistics on single-branched bypass and sequential bypass, combined with clinical features, we grouped the intraoperative bypass conditions as follows: the single-nodes of the right-crown system were respectively single-bypassed to the single-group (group A), the sequential bypass of the right coronary system and the convoluted and/or anterior descending branch system were placed in the other 
Table 1 Perioperative baseline data of patients

\begin{tabular}{|c|c|c|c|c|}
\hline Items & Sub-item & Percent\% & Count & Mean \pm standard deviation \\
\hline Age & & 100 & 242 & $62.6 \pm 8.8$ \\
\hline \multirow[t]{2}{*}{ Gender } & male & 73.6 & 178 & \\
\hline & female & 26.4 & 64 & \\
\hline Bypass count & & & & $3.22 \pm 0.803$ \\
\hline Preoperation Ejection fraction (EF) & & & & $62.3 \pm 10.3$ \\
\hline Left ventricular end diastolic diameter & & & & $5.09 \pm 0.64$ \\
\hline Smoking history & & 50 & 121 & \\
\hline Diabetes & & 40.1 & 97 & \\
\hline Hypertension & & 62.8 & 152 & \\
\hline Chronic renal insufficiency & & 1.7 & 4 & \\
\hline Extracorporeal circulation surgery & & & 88 & \\
\hline Cardiac Function Classification (NYHA Classification) & & & & $2.44 \pm 0.44$ \\
\hline Previous percutaneous coronary intervention (PCI) & & 12.8 & 31 & \\
\hline
\end{tabular}

systematic sequential groups (group C), while the right coronary system Y-bypass was placed in the PDA-PL right coronary sequential group (group B). The differences in flow, pulsation index and DF parameters between the three groups were compared. Considering that the single crown of the right crown system and one other system have a sequential influence on the flow distribution, this part of the data is ignored ( 2 cases/0.7\%) (see Table 3).

This study showed that the bypass material used in the right coronary system of our centre was mainly the saphenous vein (286 cases, $92.3 \%$ ), followed by the radial artery and the internal mammary artery, and the utilization rate of an arterial bypass was low. In the choice of target vessel sites in the right coronary system, we preferred the posterior descending artery for bypass (47.6\%), followed by the right coronary trunk (29.1\%) and the left ventricle posterior branch (23.3\%). One week after the surgery, on the coronary CT examination, 11 cases of bypass vessels had different degrees of poor development or stenosis and occlusion, and this mainly occurred in single bypass vessels (11 cases, 91.7\%), of which only one was a sequential bypass blood vessel with other systems. The differences among the above groups were statistically significant $(P<0.01) \quad$ (see Table 3).

In this study, the instantaneous flow of the vasculature in both the right coronary sequential group and the other system sequential group was higher than that of the single group, and the above difference was

Table 2 The right coronary artery system bridg method

\begin{tabular}{|c|c|c|c|}
\hline & The right crown system bypass method & Frequency & $\begin{array}{l}\text { Effective } \\
\text { percentage }\end{array}$ \\
\hline Group 1 & Non-sequential single bypass ${ }^{a}$ & 178 & 67.9 \\
\hline Group 2 & Non-sequential double bypass ${ }^{b}$ & 9 & 3.4 \\
\hline Group 3 & Posterior descending branch-posterior branch of left ventricle & 42 & 16.0 \\
\hline Group 4 & Sequential bypass with 2 gyro systems and 1 right crown system & 1 & 0.4 \\
\hline Group 5 & Sequential bypass with 1 gyro system and 1 right crown system & 20 & 7.6 \\
\hline Group 6 & Sequential bypass with one forward descend system and one right crown system & 2 & 0.8 \\
\hline Group 7 & Sequential bypass with 1 roundabout system and 2 right crown systems & 5 & 1.9 \\
\hline Group 8 & Sequential bypass with 1 forward descending system, 1 gyrating system and 1 right crown system & 2 & 0.8 \\
\hline Group 9 & Y-bypass at two target sites in the right crown system & 1 & 0.4 \\
\hline $\begin{array}{l}\text { Group } \\
10\end{array}$ & $\begin{array}{l}\text { Right target system, two target sites, one other system sequential bypass and one non-sequential single } \\
\text { branch bypass }\end{array}$ & 2 & 0.8 \\
\hline In total & & 262 & 100.0 \\
\hline
\end{tabular}

${ }^{\mathrm{a}}$ In the operation, the right crown system only has a single bypass

${ }^{b}$ In the operation, right coronary system separately set up two bypass 
Table 3 Intraoperative interventions in the right coronary system

\begin{tabular}{|c|c|c|c|}
\hline & Group & Frequency & Percentage(\%) \\
\hline \multirow[t]{4}{*}{ Bypass method } & Single bypass (Group A) & 187 & 71.9 \\
\hline & Right crown sequential group (Group B) & 43 & 16.5 \\
\hline & Sequential group with other systems (Group C) & 30 & 11.5 \\
\hline & In total & 260 & 100 \\
\hline \multirow[t]{5}{*}{ Right crown bypass material selection } & Great saphenous vein & 286 & 92.3 \\
\hline & Radial artery & 17 & 5.5 \\
\hline & Internal mammary artery & 6 & 1.9 \\
\hline & Mix bypass ${ }^{a}$ & 1 & 0.3 \\
\hline & In total & 310 & 100 \\
\hline \multirow[t]{4}{*}{ Right coronary target vessel site } & Right crown trunk & 90 & 29.1 \\
\hline & Post-fall & 147 & 47.6 \\
\hline & Posterior left ventricular branch & 72 & 23.3 \\
\hline & In total & 309 & 100 \\
\hline \multirow[t]{4}{*}{ Coronary $C T$ bypass occlusion in the week after operation } & Single bypass group & $11^{\mathrm{b}}$ & 91.7 \\
\hline & Sequential Group & 0 & 0 \\
\hline & Sequential group with other systems & 1 & 8.3 \\
\hline & In total & 12 & \\
\hline
\end{tabular}

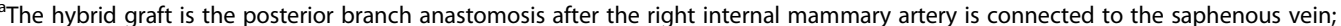

bOf the 11 cases, 4 were poorly developed, 4 were occluded (grade O), 1 was moderate to severe stenosis (grade B), and 2 were moderately stenotic (grade B)

statistically significant $(P<0.01)$. However, there was no significant difference in instantaneous bypass flow between the two sequential groups $(P=0.410)$. There was no significant difference in the pulsatility index among the three groups $(P>0.05)$. In the diastolic blood supply ratio, the right coronary sequential group was superior to the single-group $(P<0.001)$, and the difference was statistically significant, while there was no significant difference between the right coronary sequential group and the other systematic sequential groups (see Tables 4 and $5)$.

\section{Discussion}

The development of a CABG surgical strategy is one of the important factors for the success of surgery, of which the selection of target blood vessel sites is the most important strategy. Previous studies have shown that preestablished CABG surgical strategies based on coronary angiography are somewhat different from actual surgical strategies and are not related to the surgeon's seniority [4]. Regardless of whether the surgeon is a low-grade or high-grade doctor, compared with the left coronary artery system, the actual coincidence rate of the selection strategy of the targeted lesion in the right coronary system is the lowest, and this also shows to some extent that the right coronary revascularization strategy is still controversial. This study found that our centre prefers the posterior descending branch (47.6\%). Of course, this may be related to the patient's coronary lesions, but, on the other hand, may also because that, in off-pump surgery $(63.5 \%)$, the PDA is more convenient to expose and the intraoperative safety is relatively higher (compared to the right coronary trunk, less arrhythmia induced by bleeding) and other factors.

In recent years, the use of CABG for multiple arterial bypass and whole arterial bypass has become increasingly common, and a large number of studies have confirmed that these patients better mid- and long-term patency rates compared with veins $[10,11]$. This study showed that the bypass material for the right coronary system is generally the greater saphenous vein $(92.3 \%)$, which may be related to its relative safety, relatively simple acquisition, relatively sufficient material, more plasticity, and other factors. The choice of materials for the right crown bridge has always been controversial [12] Whether the high patency rate of an artery bridge on the left side is also applicable to the right side and the length of internal mammary artery, as well as the acquisition cost and the probability of a high linear sign of radial artery in the near future, all restrict the surgeon's choice of an artery to a certain extent. Our centre has little tendency to choose multi-arterial bridges, and besides strengthening our understanding, this also needs more clinical practice to shorten the learning curve.

In this study, the flow rate of the comparison between the other system sequential group (group C), the right coronary system sequential group (group B) and the single-group (group A) group gradually decreased, 
Table 4 Comparison of TTFM parameters of each group in the right coronary system

\begin{tabular}{|c|c|c|c|c|c|c|c|c|}
\hline & & \multirow[t]{2}{*}{ Mean } & \multirow[t]{2}{*}{$\begin{array}{l}\text { Standard } \\
\text { deviation }\end{array}$} & \multirow[t]{2}{*}{$\begin{array}{l}\text { Standard } \\
\text { error }\end{array}$} & \multicolumn{2}{|c|}{$\begin{array}{l}95 \% \text { confidence } \\
\text { interval for the } \\
\text { mean }\end{array}$} & \multirow[t]{2}{*}{ Minimum } & \multirow[t]{2}{*}{ Maximum } \\
\hline & & & & & $\begin{array}{l}\text { Lower } \\
\text { limit }\end{array}$ & $\begin{array}{l}\text { Upper } \\
\text { limit }\end{array}$ & & \\
\hline \multirow[t]{4}{*}{ Flow(Q) } & Single bypass (Group A) & 30.64 & 20.130 & 1.472 & 27.73 & 33.54 & 1 & 110 \\
\hline & $\begin{array}{l}\text { Right crown sequential group (Group } \\
\text { B) }\end{array}$ & 40.93 & 20.421 & 3.114 & 34.65 & 47.21 & 12 & 127 \\
\hline & $\begin{array}{l}\text { Sequential group with other systems } \\
\text { (Group C) }\end{array}$ & 45.07 & 24.458 & 4.622 & 35.59 & 54.56 & 10 & 112 \\
\hline & In total & 33.92 & 21.305 & 1.326 & 31.31 & 36.53 & 1 & 127 \\
\hline \multirow[t]{4}{*}{ Pulsation index (PI) } & Single bypass (Group A) & 3.411 & 3.4503 & .2530 & 2.912 & 3.910 & .8 & 29.8 \\
\hline & $\begin{array}{l}\text { Right crown sequential group (Group } \\
\text { B) }\end{array}$ & 3.212 & 1.6664 & .2541 & 2.699 & 3.724 & 1.4 & 8.1 \\
\hline & $\begin{array}{l}\text { Sequential group with other systems } \\
\text { (Group C) }\end{array}$ & 4.119 & 2.2009 & .4236 & 3.248 & 4.989 & 1.5 & 11.1 \\
\hline & In total & 3.452 & 3.1058 & .1941 & 3.070 & 3.835 & .8 & 29.8 \\
\hline \multirow{4}{*}{$\begin{array}{l}\text { Diastolic blood supply } \\
\text { ratio (DF) }\end{array}$} & Single bypass (Group A) & $59.78 \%$ & $11.8518 \%$ & $0.8690 \%$ & $58.065 \%$ & $61.494 \%$ & $3.0 \%$ & $84.0 \%$ \\
\hline & $\begin{array}{l}\text { Right crown sequential group (Group } \\
\text { B) }\end{array}$ & $66.881 \%$ & $10.5095 \%$ & $1.6216 \%$ & $63.606 \%$ & $70.156 \%$ & $38.0 \%$ & $88.0 \%$ \\
\hline & $\begin{array}{l}\text { Sequential group with other systems } \\
\text { (Group C) }\end{array}$ & $62.111 \%$ & $12.1603 \%$ & $2.3402 \%$ & $57.301 \%$ & $66.922 \%$ & $27.0 \%$ & $77.0 \%$ \\
\hline & In total & $61.196 \%$ & $11.9237 \%$ & $0.7467 \%$ & $59.726 \%$ & $62.667 \%$ & $3.0 \%$ & $88.0 \%$ \\
\hline
\end{tabular}

especially in the sequential group and the nonsequential groups, and the differences were statistically significant $(P<0.05)$. To some extent, the viewpoint that the sequential bypass flow was better than the singlebypass flow was verified (as the number of anastomoses increased, the flow rate gradually increased). In addition, in the non-sequential single-bypass, the peak flow of the right coronary target vessel was the highest $(37.0 \pm 21.6$ $\mathrm{ml} / \mathrm{min}$ ), and compared with the posterior descending branch $(24.7 \pm 15.5 \mathrm{ml} / \mathrm{min})$ and the left ventricle posterior branch $(26.9 \pm 23.3 \mathrm{ml} / \mathrm{min})$ had a statistically significant difference $(P<0.05)$. However, unlike the previous research results [13-15], this study showed that the left ventricular posterior tributary flow is higher than the posterior descending branch, which is not completely consistent with the classical vascular bed theory. It may be related to the number of cases, causing a certain bias.

Previous studies have shown that due to the larger number of anastomotic ports and relatively larger vascular beds, sequential bypass has a higher flow rate than single-branched bypass, and the high flow rate will delay the proliferation of the intima to a certain extent, making the bypass vessels better with an improved longterm patency rate $[13,15]$. One week after surgery, on coronary CT in the study, 11 patients in the non-

Table 5 Comparison of TTFM parameters of the right crown system (LSD method)

\begin{tabular}{|c|c|c|c|c|c|c|}
\hline \multirow[t]{2}{*}{ Parameter } & \multirow{2}{*}{$\begin{array}{l}\text { Comparison } \\
\text { between } \\
\text { groups }\end{array}$} & \multirow{2}{*}{$\begin{array}{l}\text { Mean } \\
\text { difference }\end{array}$} & \multirow{2}{*}{$\begin{array}{l}\text { Standard } \\
\text { error }\end{array}$} & \multirow[t]{2}{*}{ Significance $^{*}$} & \multicolumn{2}{|c|}{ 95\% confidence interval } \\
\hline & & & & & Lower limit & Upper limit \\
\hline \multirow[t]{3}{*}{ Flow(Q) } & $A$ vs $B$ & $-10.294^{*}$ & 3.497 & 0.004 & $-17.18^{*}$ & -3.41 \\
\hline & A vs $C$ & $-14.435^{*}$ & 4.190 & 0.001 & $-22.69^{*}$ & -6.18 \\
\hline & $B$ vs $C$ & -4.141 & 5.022 & 0.410 & -14.03 & 5.75 \\
\hline \multirow[t]{3}{*}{ Pulsation index (PI) } & $A$ vs $B$ & 0.1997 & 0.5260 & 0.705 & -0.836 & 1.236 \\
\hline & $A$ vs $C$ & -0.7072 & 0.6402 & 0.270 & -1.968 & 0.554 \\
\hline & $B$ vs $C$ & -0.9069 & 0.7633 & 0.236 & -2.410 & 0.596 \\
\hline \multirow[t]{3}{*}{ Diastolic blood supply ratio (DF) } & $A$ vs $B$ & $-7.1014 \% *$ & $1.9948 \%$ & $<0.001$ & $-11.030 \% *$ & $-3.173 \%$ \\
\hline & $A$ vs $C$ & $-2.3315 \%$ & $2.4048 \%$ & 0.333 & $-7.068 \%$ & $2.404 \%$ \\
\hline & $B$ vs $C$ & $4.7698 \%$ & $2.8803 \%$ & 0.099 & $-0.903 \%$ & $10.442 \%$ \\
\hline
\end{tabular}

*The significance level of the mean difference is 0.05 
sequential group had different degrees of stenosis or unclear visualization, but there was only one case in the sequential group. Although not necessarily caused by intimal hyperplasia, this also proves to some extent that high-flow sequential bypasses have better postoperative short-term patency [16].

In this study, coronary CT showed that poor visualization of bridging vessels was more common in radial artery bridges (4 cases). Although the related parameters such as instantaneous bridging flow during the operation were satisfactory, the poor CT results worried the surgeons who intended to carry out multi-artery or whole-artery CABG. On the premise of ensuring the correct strategy, it is still controversial as to which is more important to avoid perioperative linear symptoms by using perioperative antispasmodic drugs and/or a higher perfusion pressure. Whether there are other risk factors affecting the patency rate in the near future still needs further observation and study. This study did not refine and analyse the lesion location or stenosis degree of the right coronary artery, which may affect the surgical strategy and instantaneous blood flow results. In addition, this study is a single-centre study, and the overall sample size is small, so its results need to be further confirmed by large-scale clinical studies.

\section{Limitations}

Our study had several limitations. Due to its retrospective design, we were unable to certify that all potential confounding factors had been recorded. Our singlecentre experience may not be applicable to other institutes.

\section{Conclusion}

In our centre, the most common form of CABG in the right coronary artery system is non-sequential SV to PDA. Whether with sequential grafts of PDA-PL or other sequential grafts among the different coronary artery systems, the instantaneous flow of groups of sequential grafts was higher than that of a single graft. DF in the groups of sequential grafts of the right coronary system was better than that in the non-sequential group.

\section{Abbreviations \\ CABG: Coronary artery bypass grafting; CAD: Coronary atherosclerotic heart disease; PCI: Percutaneous coronary intervention; PI: Pulsatility index; CT: Computed tomography; TTFM: Transient-flow flow meter; MGF: Mean graft flow; DF: Diastolic flow; PDA: Posterior descending artery; RCA: Right main coronary artery; PL: Posterior branch of the left ventricle; LAD: Left anterior descending artery; LCX: Left circumflex; EF: Ejection fraction}

\section{Acknowledgements}

Not applicable.

\section{Authors' contributions}

Yu Chen is the corresponding author. Zhou Zhao and Chun Fu drafted the manuscript, Lixue Zhang and Guodong Zhang provided valuable statistical analysis for this study and participated in its design and coordination. All authors read and approved the final manuscript.

\section{Funding}

This research was supported by the Research and Development Fund of the Peking University People's Hospital, Fund Approval Number RDY2019-32. The funding source (RDY2019-32) had no role in the study design, data collection, analysis, or interpretation. The authors declare that there are no potential conflicts of interest.

\section{Availability of data and materials}

Data will be made available on request.

Ethics approval and consent to participate

Not applicable.

Consent for publication

We received explicit consent from the patients.

\section{Competing interests}

The authors declare that they have no competing interests.

\section{Author details}

${ }^{1}$ Cardiac Surgery Department, Peking University People's Hospital, Beijing 100044, China. ${ }^{2}$ Critical Care Medicine Department, Peking University People's Hospital, Beijing 100044, China.

Received: 1 April 2020 Accepted: 20 July 2020

Published online: 14 August 2020

\section{References}

1. Roth GA, Johnson C, Abajobir A, et al. Global, regional, and National Burden of cardiovascular diseases for 10 causes, 1990 to 2015. J Am Coll Cardiol. 2017;70(1):1-25.

2. Thom T, Haase N, Rosamond W, et al. Heart disease and stroke statistics-2006 update: a report from the American Heart Association statistics committee and stroke statistics subcommittee. Circulation. 2006;113(6):e85e151.

3. Hillis LD, Smith PK, Anderson JL, et al. 2011 ACCF/AHA guideline for coronary artery bypass graft surgery. A report of the American College of Cardiology Foundation/American Heart Association task force on practice guidelines. Developed in collaboration with the American Association for Thoracic Surgery, Society of Cardiovascular Anesthesiologists, and Society of Thoracic Surgeons. J Am Coll Cardiol. 2011;58(24):e123-210.

4. Wenqiang S, Yi C, Yi F, et al. Consistency of pre-planned and actual surgical strategies for coronary artery bypass grafting. Chin J Circ. 2018;33(12):11769.

5. Zhou Z, Hu L, Lixue Z, et al. Study of TTFM parameters predicting patency of graft blood vessels after 1 year after CABG. Chin J Thorac Cardiovasc Surg. 2018;34(1):40-2 55 .

6. Di Giammarco G, Pano M, Cirmeni S, et al. Predictive value of intraoperative transit-time flow measurement for short-term graft patency in coronary surgery. J Thorac Cardiovasc Surg. 2006;132(3):468-74.

7. Kieser TM, Rose S, Kowalewski R, et al. Transit-time flow predicts outcomes in coronary artery bypass graft patients: a series of 1000 consecutive arterial grafts. Eur J Cardiothorac Surg. 2010;38(2):155-62.

8. Walker PF, Daniel WT, Moss E, et al. The accuracy of transit time flow measurement in predicting graft patency after coronary artery bypass grafting. Innovations (Phila). 2013;8(6):416-9.

9. Fitzgibbon GM, Kafka HP, Leach AJ, et al. Coronary bypass graft fate and patient outcome: angiographic follow-up of 5,065 grafts related to survival and reoperation in 1,388 patients during 25 years. J Am Coll Cardiol. 1996; 28(3):616-26

10. Aldea GS, Bakaeen FG, Pal J, et al. The Society of Thoracic Surgeons clinical practice guidelines on arterial conduits for coronary artery bypass grafting. Ann Thorac Surg. 2016;101(2):801-9.

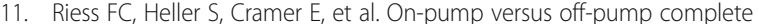
arterial revascularization using bilateral internal mammary arteries and the T-graft technique: clinical and angiographic results for 3,445 patients in 13 years of follow-up. Cardiology. 2017;136(3):170-9. 
12. Sa MP, Cavalcanti PE, Santos HJ, et al. Flow capacity of skeletonized versus pedicled internal thoracic artery in coronary artery bypass graft surgery: systematic review, meta-analysis and meta-regression. Eur J Cardiothorac Surg. 2015;48(1):25-31.

13. Wang $M$, Gao C, Bojun $L$, et al. Blood flow analysis of single saphenous vein bridge and sequential bridge during off-pump coronary artery bypass grafting. J Central South Univ (Health Sciences). 2012;37(09):901-5.

14. Christenson JT, Simonet F, Schmuziger M. Sequential vein bypass grafting: tactics and long-term results. Cardiovasc Surg. 1998;6(4):389-97.

15. Nordgaard H, Vitale N, Haaverstad R. Transit-time blood flow measurements in sequential saphenous coronary artery bypass grafts. Ann Thorac Surg. 2009;87(5):1409-15.

16. Jokinen JJ, Werkkala K, Vainikka T, et al. Clinical value of intra-operative transit-time flow measurement for coronary artery bypass grafting: a prospective angiography-controlled study. Eur J Cardiothorac Surg. 2011; 39(6):918-23.

\section{Publisher's Note}

Springer Nature remains neutral with regard to jurisdictional claims in published maps and institutional affiliations.

Ready to submit your research? Choose BMC and benefit from:

- fast, convenient online submission

- thorough peer review by experienced researchers in your field

- rapid publication on acceptance

- support for research data, including large and complex data types

- gold Open Access which fosters wider collaboration and increased citations

- maximum visibility for your research: over $100 \mathrm{M}$ website views per year

At BMC, research is always in progress.

Learn more biomedcentral.com/submissions 